\title{
Causes of Granulomatous Inflammation in Native and Allograft Kidneys: Case Series from A Single Center and A Review of the Literature
}

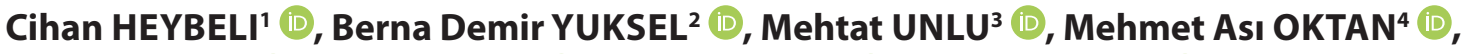

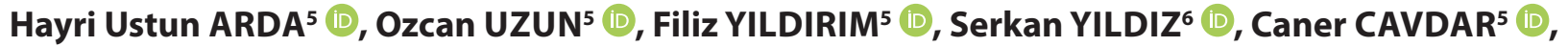 \\ Aykut SIFIL 5 (D) Ali CELIK ${ }^{4} \mathbb{D}$, Sulen SARIOGLU ${ }^{3}$ (D) \\ 'Division of Nephrology, Muş State Hospital, Muş, TURKEY \\ Department of ${ }^{2}$ Internal Medicine, ${ }^{3}$ Pathology Dokuz Eylul University Hospital, Izmir, TURKEY \\ Division of Nephrology, ${ }^{4}$ Baskent University Hospital, Izmir, TURKEY, ${ }^{5}$ Dokuz Eylul University Hospital, Izmir, TURKEY, ${ }^{6}$ Medicana Hospital, Izmir, TURKEY
}

\section{ABSTRACT}

Objective: Granulomatous interstitial nephritis is a rare finding, and etiology differs by geography. We aimed to investigate the distribution of causes of granuloma/granulomata in the kidney and renal survival of these patients in a tertiary care hospital in Western Turkey.

Material and Method: Medical records of adults who underwent a kidney biopsy procedure in our institution between January 2000 and June 2019 were reviewed. Pathology reports were searched for biopsies where a granuloma was identified.

Results: Nineteen of 1121 (1.7\%) kidney biopsies included granuloma, 17 in native kidneys, and 2 in transplants. The majority of indications for native kidney biopsy was a rise in serum creatinine. Etiologies of granuloma included the following: pauci-immune vasculitis ( $\mathrm{n}=11,64.7 \%$ ), tuberculosis $(n=2,11.8 \%)$, drug-induced $(n=2,11.8 \%)$, tubulointerstitial nephritis/uveitis (TINU) syndrome ( $n=1,5.9 \%)$, and systemic-lupus erythematosus $(n=1,5.9 \%)$. Despite treatment, 6 of 11 (54.5\%) patients with vasculitis developed end-stage kidney disease (ESKD) during the median follow-up of 16 months. Both of the patients with tuberculosis, and the patient with TINU syndrome developed ESKD months after the kidney biopsy, despite appropriate therapies. The only case with drug-induced granuloma and both cases with allograft kidney granuloma responded well to glucocorticoids, achieving a complete renal recovery.

Conclusion: The majority of our series had granuloma in the kidney secondary to vasculitis and renal outcomes appear considerably unfavorable despite treatment, probably related to the primary diagnosis. Multicenter studies are needed to better determine the etiology and outcome of each granuloma etiology at different geographic locations.

Keywords: Granuloma, Renal biopsy, Pathology, Renal

\section{INTRODUCTION}

Granulomatous interstitial nephritis (GIN) is a histological diagnosis which comprises less than $1 \%$ of all kidney biopsies (1). The primary etiology is wide an includes various systemic inflammatory disorders such as granulomatous polyangitis (GPA), sarcoidosis (2-5), Crohn's disease (6), Sjögren syndrome (7), malignancies such as chronic lymphocytic lymphoma $(8,9)$, fungal infections $(10,11)$, and mycobacterial infections $(12,13)$. Numerous drugs may also cause GIN and these include diuretics (14), proton-pump inhibitors $(15,16)$, nonsteroidal anti-inflammatory drugs $(17,18)$, zoledronic acid (19), captopril (20), ciprofloxacin (21), vancomycin (22), anti-TNF agents $(23,24)$, tramadol $(25)$, atazanavir $(26,27)$, and immunotherapy with ipilimumab and nivolumab (28).
It is not straightforward to differentiate between these causes using renal histology alone, and the diagnosis is usually made based on the clinical presentation and extrarenal findings $(29,30)$. The most common cause differs between geographical regions. Drug-induced GIN and renal involvement of sarcoidosis are quite common along with idiopathic GIN in Western countries $(31,32)$, whereas tuberculosis is the most common cause of GIN in endemic areas such as India $(12,13)$.

The number of studies on granuloma/granulomata formation in kidney is quite limited. Despite the endemicity of tuberculosis, there is no data on the prevalence of GIN in Turkey. We therefore aimed to investigate the causes of granuloma formation in the kidney and analyze long-term outcomes of these patients. 


\section{MATERIALS and METHODS}

Medical records of adults ( $\geq 18$ years of age) who underwent a kidney biopsy procedure at Dokuz Eylul University Hospital between January 2000 through June 2019 were reviewed. Kidney biopsies of adult patients $(\geq 18$ years of age) with tissue sufficient to make the diagnosis were included in the study. Patients who had granuloma/ granulomata formation in kidney biopsy specimens were determined. Given the numerous etiological factors for granuloma/granulomata formation, all subjects underwent a detailed evaluation in order to determine the cause. The following data were recorded: demographic details, comorbid diseases, drug exposures, clinical findings at the time of presentation, urinalysis, full blood count, serum biochemistry (creatinine, calcium, albumin, liver function tests), autoantibodies (antinuclear antibody [ANA], antineutrophil cytoplasmic antibody [ANCA]), complement C3 and C4, viral serology tests (hepatitis B, hepatitis C, human immunodeficiency virus), ultrasonography of the abdomen, and chest $\mathrm{x}$-ray. The following work-up was carried out patients with no apparent cause for granuloma formation (excluding drug exposures): angiotensinconverting enzyme (ACE) levels, cytomegalovirus and Epstein-Barr virus serologies, acid fast bacilli in the urine, polymerase chain reaction and culture of mycobacterium tuberculosis on bronchoalveolar lavage specimens, and computed tomography of the chest and abdomen.

The date of kidney biopsy was recorded as the baseline for laboratory records. Acute kidney injury was defined according to consensus criteria (33). Rapidly progressive glomerulonephritis was defined as the loss of kidney function within days to weeks along with remarkable findings in urinalysis (34). Microscopic hematuria was accepted if $>3$ red blood cells per high power field were seen in urine microscopy (35). End-stage kidney disease (ESKD) was defined according to consensus criteria (36). Given that the majority of cases presented with a rise in serum creatinine, the definition of response to therapy was made as follows. Complete response was a return of serum creatinine to $<0.35 \mathrm{mg} / \mathrm{dL}$ above the baseline value and partial response was a return of serum creatinine to $>.0 .35$ $\mathrm{mg} / \mathrm{dL}$ but less than twice the baseline value (37).

\section{Renal Histopathology}

Histological data was retrieved from pathology reports. Renal biopsy specimens were evaluated using hematoxylin-eosin, Masson's trichrome, periodic acid schiff, and methenamine silver stained sections by light microscopy. Immunofluorescent analysis was made after staining for antibodies against immunoglobulins G-A-M, complement components $\mathrm{C} 3$ and $\mathrm{C} 1 \mathrm{q}$, and kappa and lambda light-chains for immunofluorescence. Electron microscopic evaluation was not routinely performed. Previous studies used the term GIN if at least 1 granuloma in kidney sections was found (32). For this study, we have used the term "granuloma/granulomata formation" since there is no consensus for the definition of GIN. Given that tuberculosis is endemic in our country, Ziehl-Neelsen staining was performed on kidney sections of patients with a history of pulmonary tuberculosis, on allograft kidney with granulomatous inflammation, and on patients with no identified cause of granuloma formation.

\section{Statistical Analysis}

Quantitative variables were expressed as median with the range (minimum-maximum). Qualitative variables were expressed as proportions. Overall renal survival was estimated using the Kaplan-Meier method. Statistical analysis was performed using SPSS 22.0 version (IBM SPSS, Chicago, IL).

\section{RESULTS}

Granuloma was identified in 19 of 1121 (1.7\%) kidney biopsies performed in our hospital between 2007-2019. The median age at the time of kidney biopsy was 60 (range, $20-84)$, and 12 (63.2\%) were male. Two of the biopsies were allograft kidney biopsies and seventeen were native kidney biopsies.

\section{Native Kidney Granuloma/Granulomata}

Of the 17 native kidney granulomata, 11 (64.7\%) were male and the median age was 60 (range, 21-84). At baseline, hypertension and diabetes mellitus constituted 52.9\% (9 patients) and $29.4 \%$ (5 patients) of the cohort. Indications for kidney biopsy included acute kidney injury (AKI) in 12 (70.6\%), rapidly progressive glomerulonephritis (RPGN) in $4(23.5 \%)$, and asymptomatic urinary abnormalities in $1(5.9 \%)$ case. The following etiologies were captured after the detailed evaluation: pauci-immune vasculitis $(\mathrm{n}=11,64.7 \%)$, tuberculosis $(\mathrm{n}=2,11.8 \%)$, drug-induced $(\mathrm{n}=2,11.8 \%)$, tubulointerstitial nephritis/uveitis (TINU) syndrome $(\mathrm{n}=1,5.9 \%)$, and systemic-lupus erythematosus $(\mathrm{n}=1,5.9 \%)$. Detailed description of each native kidney granuloma is given in Table I.

\section{Pauci-Immune Vasculitis}

The median age of these patients was 60 (range, 28-84), and $7(63.6 \%)$ were male. Clinical presentations were as follows: AKI (6 patients, 54.5\%), RPGN (4 patients, 30.8\%), and 
Table I: Characteristics, treatments, and outcomes of patients with granulomatous inflammation of the native kidney.

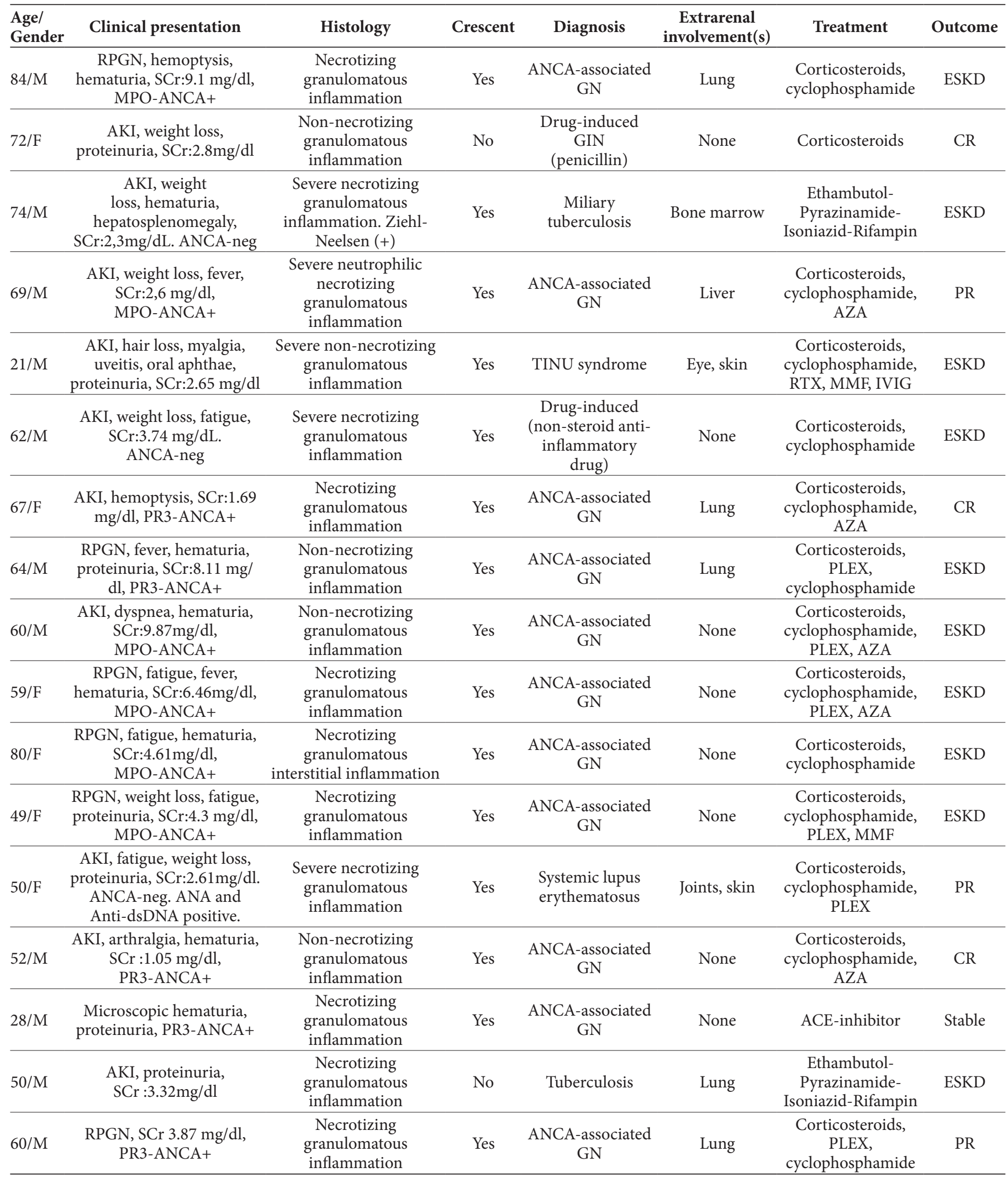

AKI: Acute kidney injury, AZA: Azathioprine, CR: Complete remission, ESKD: End-stage kidney disease, GN: Glomerulonephritis, MMF: Mycophenolate mofetil, NR: No response, PLEX: Plasma exchange, PR: Partial remission, RPGN: Rapidly progressive glomerulonephritis, RTX: Rituximab, SCr: Serum creatinine. 
asymptomatic urinary abnormalities (1 patient, 7.7\%). The median serum creatinine at baseline was 4.46 (range, 1.699.87) $\mathrm{mg} / \mathrm{dL}$. Six patients required hemodialysis at the time of diagnosis. Seven of these had positive antibodies against myeloperoxidase (MPO-ANCA), and 4 had positive antibodies against proteinase-3 (PR3-ANCA). All of these patients were pauci-immune based on immunofluorescence microscopy findings. Lung involvement was evident in 5 (38.5\%) of patients. Histology was remarkable for severe necrotizing granulomatous inflammation with crescent formation in the majority (Figure 1). All subjects received glucocorticoids while some were also treated with a mixture of cyclophosphamide, plasma exchange, azathioprine, and/or mycophenolate mofetil. Among the 10 patients who presented with AKI or RPGN, 6 had no response, 2 had partial response, and 2 achieved a complete response. The patient who had asymptomatic urinary abnormalities did not receive immunosuppressive therapy and findings in urine persisted following therapy with angiotensinconverting enzyme inhibitor. During the median follow-up of 16 (range, 1-84) months, 6 (54.5\%) patients developed ESKD and 2 (18.2\%) of them died.

\section{Tuberculosis}

Two patients had tuberculosis of the kidney. Both subjects already had a diagnosis of tuberculosis of the lung by polymerase chain reaction and sputum culture prior to kidney biopsy.

The first patient was a 74-year-old-male with long-standing hypertension. The clinical presentation was AKI, with a serum creatinine level of $2.3 \mathrm{mg} / \mathrm{dL}$. Kidney functions deteriorated and hemodialysis was initiated. There was a history of lung tuberculosis and Ziehl-Neelsen staining was positive in the kidney. In addition to severe necrotizing granulomatous inflammation, there was also crescent formation in the histology. A subsequent bone marrow biopsy also showed severe granulomatous inflammation.

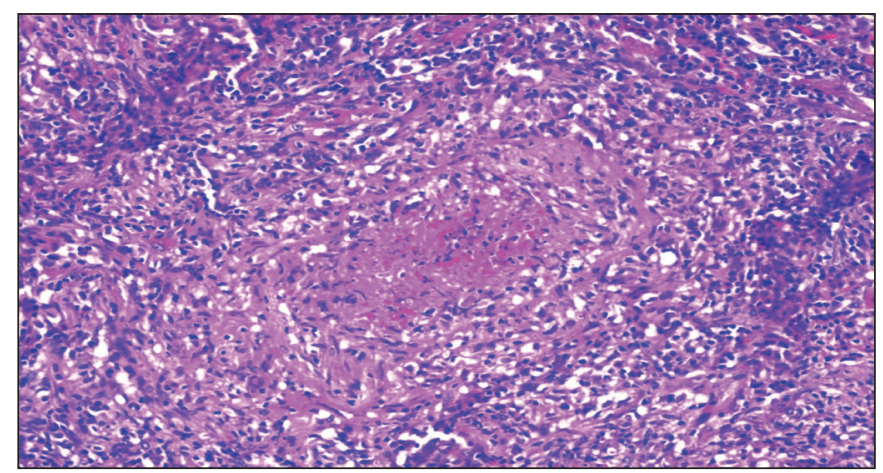

Figure 1: Necrotizing granulomatous interstitial inflammation in a case with granulomatous microscopic polyangiitis ( $\mathrm{H} \& \mathrm{E}, \mathrm{x} 40)$.
The patient received a combination of rifampin, isoniazide, ethambutol, and pyrazinamide, but could not come off dialysis. Unfortunately, the patient died 3 months after the kidney biopsy.

Indication for kidney biopsy in the second patient, a 50-year-old male, was AKI, with a serum creatinine of $3.32 \mathrm{mg} / \mathrm{dL}$. Nephrotic syndrome was also evident, with 7.9 grams/24 hours of urinary protein excretion. Kidney biopsy showed severe necrotizing granulomatous intersitial nephritis. The same treatment protocol was given for tuberculosis. Unfortunately, the patient developed ESKD within 3 months after the kidney biopsy. Although both cases had a rise in serum creatinine after hospitalization, baseline serum creatinine levels were not known. They were both HIV-negative. Kidney histology revealed moderate to severe interstitial fibrosis/tubular atrophy, suggesting a preceding chronic damage.

\section{Tubulointerstitial Nephritis/Uveitis (TINU) Syndrome}

The patient with TINU syndrome was a 21-year-oldmale, who was admitted to the hospital for allopecia totalis, red eye, and malaise. Examination of the eye was compatible with anterior uveitis. Serum creatinine was 3.3 $\mathrm{mg} / \mathrm{dL}$ and proteinuria was subnephrotic. Urine sediment showed pyuria but no microhematuria. Serological workup was unremarkable. Kidney histology showed severe tubulointerstitial granulomatous inflammation with mild interstitial fibrosis and crescent formation. There was non-necrotizing granulomatous inflammation (Figure 2). Following treatment with cyclophosphamide and glucocorticoids, the alopecia and uveitis completely resolved with a mild improvement in kidney functions. However, kidney functions deteriorated during the following year requiring permanent dialysis, despite therapy with mycophenolate mofetil, rituximab, and intravenous immunoglobulin.

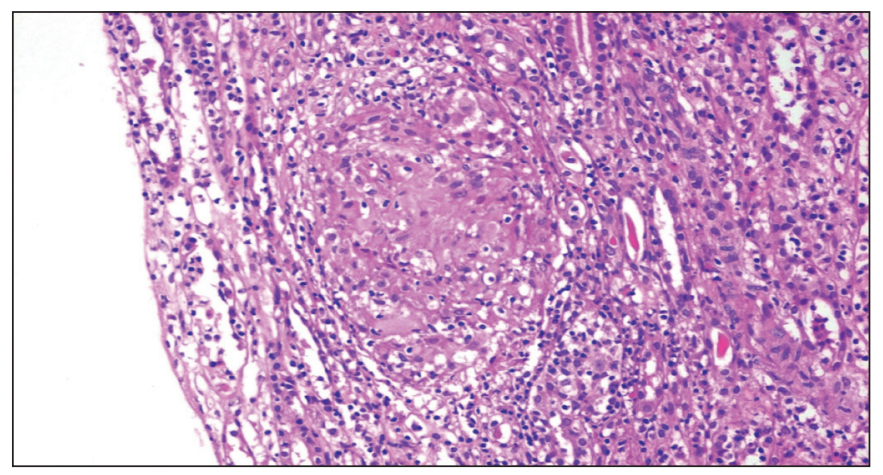

Figure 2: Non-necrotizing granulomatous interstitial inflammation in a case with tubulointerstitial nephritis/uveitis (TINU) syndrome (H\&E, x40). 


\section{Drug-Induced GIN}

The first patient with drug-induced GIN, a 72-year-old woman, presented with AKI. Abnormal test results included a serum creatinine of $2.8 \mathrm{mg} / \mathrm{dl}$ with mild ( $<1 \mathrm{~g} /$ day $)$ proteinuria and pyuria, but no microhematuria. Penicillin was given for upper respiratory tract infection a week before the AKI event. Kidney biopsy showed granulomatous inflammation and mild interstitial fibrosis and tubular atrophy (IFTA). Work-up for possible other etiologies such as tuberculosis, sarcoidosis, and inflammatory rheumatic diseases were unremarkable. Glucocorticoids provided a complete remission with no further relapse during the following 63 months of follow-up.

The second patient was a 62-year-old male with longstanding hypertension and diabetes. The presentation was AKI, with a serum creatinine of $3.74 \mathrm{mg} / \mathrm{dL}$, which climbed from a baseline of $1.5 \mathrm{mg} / \mathrm{dL}$. Urine sediment was active and the kidney biopsy showed severe necrotizing granulomatous interstitial nephritis with multiple multinucleated giant cells, and crescent formation. A detailed work-up including ANA and ANCA tests, serum calcium, hepatitis serology, ACE levels, and chest CT were unremarkable. The patient stated that he received daily non-steroid anti-inflammatory drugs within the last 2 weeks for headache. Due to crescents in histology, the patient received a combination of corticosteroids and cyclophosphamide. Unfortunately, he developed ESKD with no response to therapy during the follow-up of 6 months.

\section{Systemic Lupus Erythematosus}

This was a 50-year-old woman with a history of chronic polyarthritis in small joints of the hand. Her presentation was with AKI, with a serum creatinine of $2.61 \mathrm{mg} / \mathrm{dL}$. Baseline serum creatinine was told to be normal. There was approximately $3 \mathrm{~g} / 24$ hours of urinary protein excretion, but no hematuria. A kidney biopsy showed severe necrotizing granulomatous interstitial nephritis with crescent formation. Immunofluorescence was negative for immunoglobulins and complement. ANA and Antidouble stranded DNA (Anti-dsDNA) results were positive. Induction immunosuppression included corticosteroid and cyclophosphamide. The patient had partial response and she was maintained with azathioprine. After partial response, kidney functions remained stable with no further relapse during the follow-up of 52 months.

Among all patients with native kidney granuloma formation, the median follow-up was 24 months. Ten (58.8\%) patients developed ESKD, and 4 (23.4\%) died. Overall, the median estimated renal survival of 17 patients with granuloma/granulomata in the native kidney was 12 months.

\section{Granuloma in the Allograft Kidney}

The first patient with granuloma in the allograft kidney, a 49-year-old female, had allograft dysfunction 7 years after the kidney transplantation. The primary etiology of ESKD was chronic pyelonephritis. Serum creatinine during allograft biopsy was $1.1 \mathrm{mg} / \mathrm{dL}$, which increased from a baseline of $0.7 \mathrm{mg} / \mathrm{dL}$. Urine tests showed a subnephrotic proteinuria and microhematuria. Biopsy showed granulomatous inflammation with crescents. There was no lung or upper respiratory-tract involvement. Detailed work-up including ANCA tests and other autoantibodies were all negative. Following glucocorticoid therapy (1 mg/ $\mathrm{kg}$ ), she achieved a complete remission with the serum creatinine returning to baseline levels around $0.7 \mathrm{mg} /$ dl. Renal function remained stable for the following 68 months.

The second patient with granuloma in the allograft kidney was a 20-year-old male. He presented with a rising serum creatinine, from $1.2 \mathrm{mg} / \mathrm{dL}$ to $2.67 \mathrm{mg} / \mathrm{dL}$. This was 11 years after the kidney transplantation and the primary etiology of the ESKD was chronic glomerulonephritis. Native kidney biopsy was compatible with immunecomplex glomerulonephritis (including $\mathrm{Clq}$ positivity on immunofluorescence microscopy) but no granuloma, ANA and ANCA tests were negative. After a detailed evaluation, the cause of granuloma formation could not be found, and the etiology was deemed to be idiopathic. With the introduction of $1 \mathrm{mg} / \mathrm{kg}$ of glucocorticoids and continuation of mycophenolate mofetil with calcineurininhibitor, he achieved a complete response with a serum creatinine returning close to the baseline levels of $1.4 \mathrm{mg} /$ dL.

\section{DISCUSSION}

With this case series, we have observed that the ANCAassociated vasculitis was the most common cause of granuloma formation in the kidney. The number of patients with tuberculosis of the kidney is probably overlooked, since kidney biopsy is rarely performed in patients with tuberculosis of the lung. There were only a few patients who had acute onset disease with GIN, while the majority had more chronic onset diseases, such as chronic rheumatic conditions, vasculitis, and infections.

Previous reports included several cases with sarcoidosis of the kidney (38); yet we have not observed any, despite detailed diagnostic tests such as angiotensin-converting 
enzyme levels, computed tomography, and bronchoscopy were performed. Excluding 2 cases of drug-induced GIN and 2 allograft biopsies, more than half of our patients developed ESKD. This is probably be due to the high frequency of glomerulonephritis with crescents in our cohort and low number of cases with drug-induced GIN and absence of sarcoidosis, rather than granuloma formation itself. Thus, diseases causing acute granulomatous inflammation in the kidney, which may respond better to treatment were less frequently observed in our cohort. Indeed, Zajjari et al. stated that the outcome was good in patients with drug-induced GIN or sarcoidosis (39). In contrast to the outcomes of our patients, Joss et al. reported quite acceptable renal response to therapies (32). However, the authors excluded cases with crescents from their study, as these were accepted as secondary GIN. We have not excluded these subjects, since GIN frequently occurs secondary to a systemic disease such as autoimmune disorders or particular infections. Crescent formation was also evident in one of our patients with tuberculosis and the one with TINU syndrome, which would be another argument to support the inclusion of patients with crescents.

Crescent formation with granulomatous inflammation is characteristic of granulomatous polianjitis (GPA), yet granulomatous inflammation is frequently seen in lung biopsies rather than kidney specimens (40). It is not known whether renal survival is worse among subjects with GPA who have granulomatous inflammation in the kidney versus GPA without renal granulomatosis. This issue requires further study. In a multicenter study, kidney biopsies of patients with pauci-immune crescentic glomerulonephritides were classified according to the extent of the lesions in the Bowman space, and the authors used the term "full moon" for those who had circumferential crescents (41). The main message of the paper was that patients with full moon crescents had more unfavorable renal survival. Interestingly, granuloma formation was more common in patients with full moon crescents. Among the pauci-immune glomerulonephritides, GPA and eosinophilic GPA are known to cause granulomatous inflammation. Although ANCA against proteinase (c-ANCA) is usually the positive antibody found in GPA, p-ANCA positivity was more common in this cohort.

Another typical chronic disease that may cause granulomatous inflammation in the kidney is tuberculosis. Renal tuberculosis is easily overlooked, and the diagnosis sometimes made post-mortem (42). The unfavorable outcomes of our 2 cases with renal tuberculosis may be due to the delayed diagnosis. Moreover, despite a high index of clinical suspicion, the diagnosis of GIN secondary to tuberculosis may be difficult and require PCR-based techniques (43). Microorganisms may not be detected in histological examination of the kidney. Ziehl-Neelsen staining helped only in 1 of 9 cases in the study by Agrawal and co-workers (43). The Ziehl-Neelsen stain result was positive in 1 of 2 our cases with tuberculosis. Some authors recommend combining the auramine $\mathrm{O}$ stain in order to increase sensitivity and specificity for the detection of tuberculosis (44). Timely diagnosis and early treatment of tuberculosis is associated with more favorable outcomes (42). GIN due to tuberculosis is even more common among subjects infected with HIV, and is associated with increased mortality in that case (45). None of our cases were HIVpositive. Similar to our paper, tuberculosis was not the predominant etiology in some of the previous reports from endemic locations (46).

One chronic systemic inflammatory disease causing GIN is the TINU syndrome. The presentation as GIN is quite rare for this syndrome (30). The presence of a crescent in our patient with TINU is also unusual. Another unexpected thing in our case is the unfavorable outcome, despite the prescription of a mixture of immunosuppressive drugs including glucocorticoids, cyclophosphamide, and rituximab. The patient uneventfully developed ESKD and was maintained on hemodialysis. Our case is the exception rather than the rule, and more studies are needed to delineate the prognostic impact of TINU syndrome on kidney outcomes.

Similar to native kidney GIN, the etiological factors are numerous in allograft kidney GIN, including several acute and chronic disorders. Infections are the most common cause of GIN in allograft kidneys (47). For transplant patients, it is important to determine if the etiology of ESKD recurs after kidney transplantation. Data for transplant kidney GIN are more lacking and come from case reports (Table II). It is not clear if GIN recurs after kidney transplantation. However, recurrences of sarcoidosis (48), idiopathic GIN (49), TINU (50, 51), and crescentic GN (47) were reported. The potential to recur probably depends on the etiology but the majority of case reports and the data from our study indicate a favorable survival in most patients, although some developed graft loss. Concurrent rejection episodes may occur and contribute to graft failure in some patients with GIN (52).

Our study contains a number of limitations. This was a descriptive study with a small sample size, and etiologies of renal granuloma were determined retrospectively. In the majority of our cases, GIN was probably caused by 
Table II: Reports of Granulomatous Interstitial Nephritis in Allograft Kidneys.

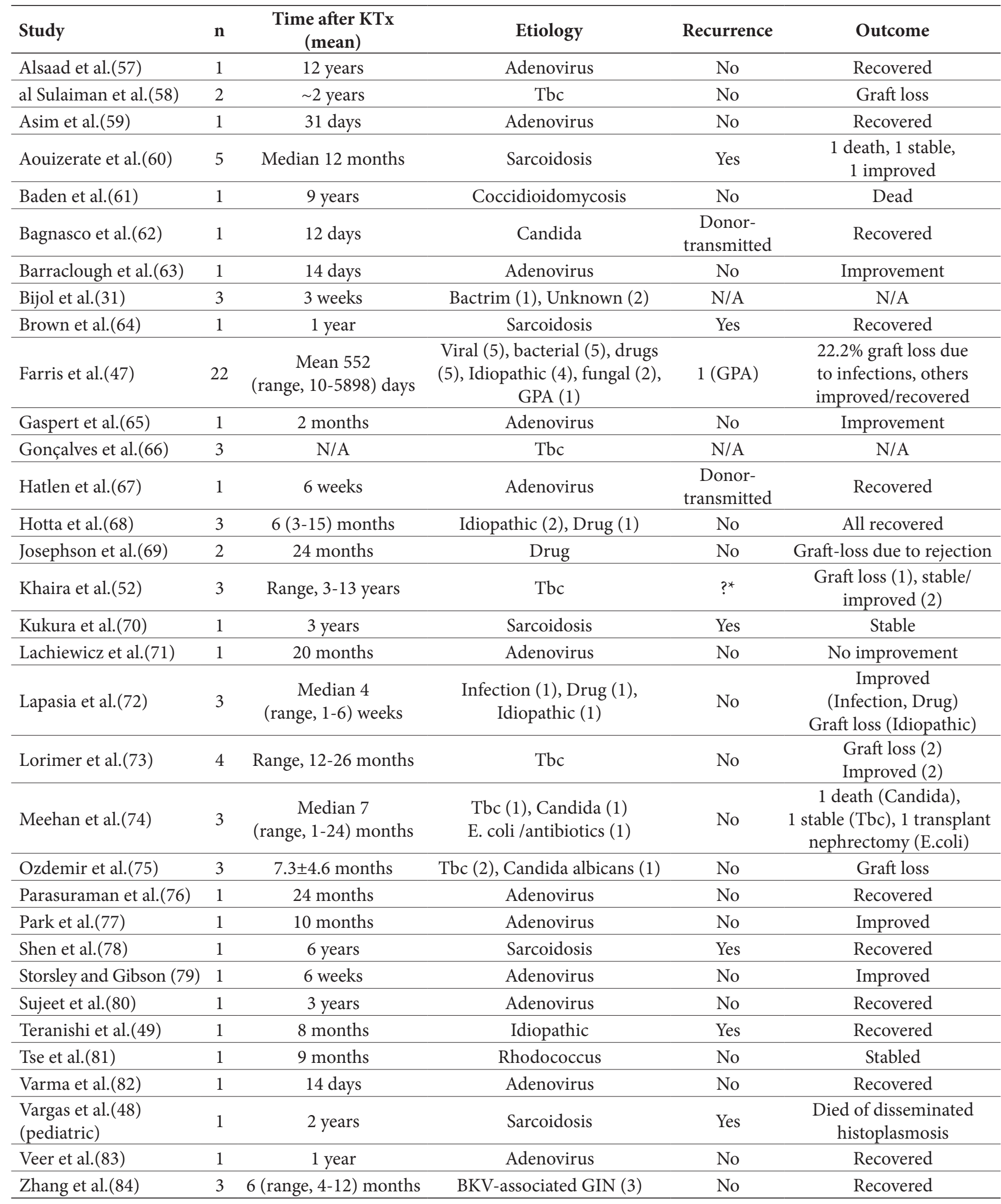

${ }^{\star}$ Etiology of ESKD was unknown in 1 case. CR: Complete remission, GPA: Granulomatous polyangiitis, N/A: Not available, PR: Partial remission, Tbc: Tuberculosis 
chronic kidney damage, and it may not be reasonable to compare outcomes of acute causes of GIN versus those with subacute/chronic damage. Despite these significant limitations however, there are only a few studies on GIN and our data shows the considerably unfavorable renal survival of patients, unlike previous case series (Table
III). This is particularly the case for patients with chronic causes GIN, such as GPA. All of our cases had granuloma/ granulomata formation but it is not clear if all of them should be regarded as GIN. There is no consensus for the definition of GIN, and this issue should be studied. Effects of granuloma formation on kidney outcomes may not be the

Table III: Previous Studies on Native Kidney Granulomatous Interstitial Nephritis

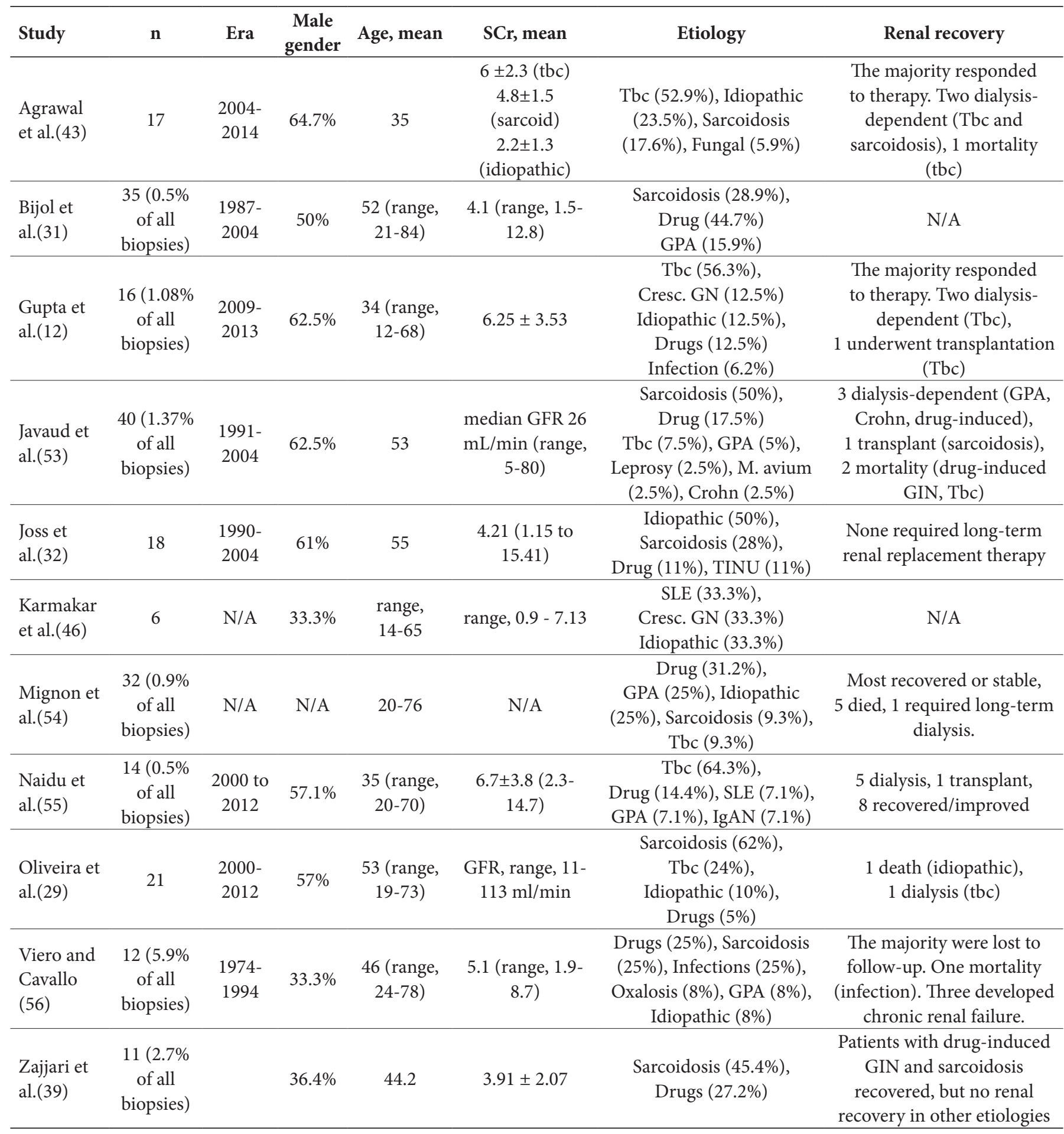

Cresc. GN: Crescentic glomerulonephritis, GPA: Granulomatous polyangiitis, IgAN: IgA nephropathy, N/A: Not available, Tbc: Tuberculosis. 
same for each etiology, and it may not be straightforward to use a common definition for all. Apparently, acute and chronic causes of GIN should be separately evaluated.

In conclusion, ANCA-associated vasculitis appeared to be the most common cause of granuloma formation in the kidney in our study. Renal survival is significantly shortened and multicenter studies are needed in order to delineate the nature of different etiologies of granuloma formation in the kidney, and determine the best treatment option for each category.

\section{Conflict of Interest}

The authors declare no conflict of interest.

\section{Ethics approval}

This study was approved by the Ethics Committee of Dokuz Eylül University School of Medicine (IRB code: 2019/17-230307).

\section{Informed consent}

Informed consent was waived due to the retrospective design, confidentiality of patient identity, and absence of any invasive procedures.

\section{Authorship Contributions}

Concept: CH, BDY, MAO, SS, Design: CH, Data collection or processing: CH, BDY, MÜ, HÜA, ÖU, FY, SY, Analysis of Interpretation: CH, BDY, MÜ, HÜA, ÖU, FY, SY, MAO, AÇ, AS, CÇ, SS, Literature search: CH, BDY, Writing: CH, BDY, SS, Approval: CH, BDY, MÜ, HÜA, ÖU, FY, SY, MAO, AÇ, AS, CÇ, SS.

\section{REFERENCES}

1. Shah S, Carter-Monroe N, Atta MG. Granulomatous interstitial nephritis. Clin Kidney J. 2015;8:516-23.

2. O'Riordan E, Willert RP, Reeve R, Kalra PA, O'Donoghue DJ, Foley RN, Waldek S. Isolated sarcoid granulomatous interstitial nephritis: Review of five cases at one center. Clin Nephrol. 2001; 55:297-302.

3. Robson MG, Banerjee D, Hopster D, Cairns HS. Seven cases of granulomatous interstitial nephritis in the absence of extrarenal sarcoid. Nephrol Dial Transplant. 2003;18:280-4.

4. Tsukada H, Shimizu H, Kaname S. Bilateral nephromegaly due to isolated renal sarcoidosis. Clin Exp Nephrol. 2017;21:169-70.

5. Utas C, Dogukan A, Patiroglu TE, Oymak S, Oymak O. Granulomatous interstitial nephritis in extrapulmonary sarcoidosis. Clin Nephrol. 1999;51:252-4.

6. Timmermans SA, Christiaans MH, Abdul-Hamid MA, Stifft F, Damoiseaux JG, van Paassen P. Granulomatous interstitial nephritis and Crohn's disease. Clin Kidney J. 2016;9:556-9.

7. Bitik B, Gonul, II, Haznedaroglu S, Goker B, Tufan A. Granulomatous interstitial nephritis associated with Primary Sjogren's syndrome. Z Rheumatol. 2017;76:458-60.
8. Inoue T, Sato T, Okada H, Kayano H, Watanabe Y, Kikuta T, Tsuda M, Sueyoshi K, Takenaka T, Suzuki H. Granulomatous interstitial nephritis in chronic lymphocytic leukaemia. Nephrol Dial Transplant. 2010;25:4107-9.

9. Nasr SH, Shanafelt TD, Hanson CA, Fidler ME, Cornell LD, Sethi S, Chaffee KG, Morris J, Leung N. Granulomatous interstitial nephritis secondary to chronic lymphocytic leukemia/small lymphocytic lymphoma. Ann Diagn Pathol. 2015;19:130-6.

10. Nasr SH, Koscica J, Markowitz GS, D’Agati VD. Granulomatous interstitial nephritis. Am J Kidney Dis. 2003;41:714-9.

11. Ogura M, Kagami S, Nakao M, Kono M, Kanetsuna Y, Hosoya T. Fungal granulomatous interstitial nephritis presenting as acute kidney injury diagnosed by renal histology including PCR assay. Clin Kidney J. 2012;5:459-62.

12. Gupta P, Rana DS, Bhalla AK, Gupta A, Malik M, Gupta A, Bhargava V. Renal failure due to granulomatous interstitial nephritis in native and allograft renal biopsies: Experience from a tertiary care hospital. Ren Fail. 2014;36:1468-70.

13. Sampathkumar K, Sooraj YS, Mahaldar AR, Ramakrishnan M, Rajappannair A, Nalumakkal SV, Erode E. Granulomatous interstitial nephritis due to tuberculosis-a rare presentation. Saudi J Kidney Dis Transpl. 2009;20:842-5.

14. Enriquez R, Cabezuelo JB, Gonzalez C, Lacueva J, Teruel A, Fernandez J, Arenas MD. Granulomatous interstitial nephritis associated with hydrochlorothiazide/amiloride. Am J Nephrol. 1995; 15:270-3.

15. Geevasinga N, Coleman PL, Roger SD. Rabeprazole-induced acute interstitial nephritis. Nephrology. (Carlton) 2005;10:7-9.

16. Nadri Q, Althaf MM. Granulomatous tubulointerstitial nephritis secondary to omeprazole. BMJ Case Rep. 2014;2014.

17. Jung K, Zeng X, Bilusic M. Nivolumab-associated acute glomerulonephritis: A case report and literature review. BMC Nephrol. 2016;17:188.

18. Schwarz A, Krause PH, Keller F, Offermann G, Mihatsch MJ. Granulomatous interstitial nephritis after nonsteroidal antiinflammatory drugs. Am J Nephrol. 1988;8:410-6.

19. Avgustin N, Kovac D, Kojc N, Mlinsek G, Lindic J. Acute granulomatous interstitial nephritis and acute rejection in a kidney transplant recipient after zoledronic acid therapy - a case report and review of the literature. Clin Nephrol. 2017;88:97-100.

20. Islam S, Dubigeon MP, Guenel J. Acute and reversible interstitial granulomatous nephropathy after treatment with captopril. Rev Med Interne. 1990;11:231-3.

21. Goli R, Mukku KK, Raju SB, Uppin MS. Acute CiprofloxacinInduced Crystal Nephropathy with Granulomatous Interstitial Nephritis. Indian J Nephrol. 2017;27:231-3.

22. Hong S, Valderrama E, Mattana J, Shah HH, Wagner JD, Esposito M, Singhal PC. Vancomycin-induced acute granulomatous interstitial nephritis: Therapeutic options. Am J Med Sci. 2007; 334:296-300

23. Korsten P, Sweiss NJ, Nagorsnik U, Niewold TB, Grone HJ, Gross O, Muller GA. Drug-induced granulomatous interstitial nephritis in a patient with ankylosing spondylitis during therapy with adalimumab. Am J Kidney Dis. 2010;56:e17-21. 
24. Sandys V, Moloney B, Lane L, Qazi J, Doyle B, Barry M, Leavey S, Conlon P. Granulomatous interstitial nephritis secondary to adalimumab therapy. Clin Kidney J. 2018;11:219-21.

25. Borrego Utiel FJ, Luque Barona R, Perez Del Barrio P, Borrego Hinojosa J, Ramirez Tortosa C. Acute Kidney Injury due to granulomatous interstitial nephritis induced by tramadol administration. Nefrologia. 2018;38:227-8.

26. Chu GJ, Henderson C, Evans L, Howlin K, Murad A. Chronic granulomatous interstitial nephritis and urothelial metaplasia associated with ritonavir-boosted atazanavir: A case study and literature review. Pathology. 2018;50:565-8.

27. Varghese V, Rodriguez R, Self S, Velez JCQ. Atazanavir CrystalInduced Chronic Granulomatous Interstitial Nephritis. Kidney Int Rep. 2020;5:1106-10.

28. Bottlaender L, Breton AL, de Laforcade L, Dijoud F, Thomas L, Dalle S. Acute interstitial nephritis after sequential ipilumumab - nivolumab therapy of metastatic melanoma. J Immunother Cancer. 2017;5:57.

29. Oliveira B, Jayawardene S, Shah S. Single-centre experience of granulomatous interstitial nephritis-time for a new approach? Clin Kidney J. 2017;10:249-54.

30. Shah KK, Pritt BS, Alexander MP. Histopathologic review of granulomatous inflammation. J Clin Tuberc Other Mycobact Dis. 2017;7:1-12.

31. Bijol V, Mendez GP, Nose V, Rennke HG. Granulomatous interstitial nephritis: A clinicopathologic study of 46 cases from a single institution. Int J Surg Pathol. 2006;14:57-63.

32. Joss N, Morris S, Young B, Geddes C. Granulomatous interstitial nephritis. Clin J Am Soc Nephrol. 2007;2:222-30.

33. KDIGO clinical practice guideline for acute kidney injury. Kidney Int Suppl. 2012;2:1-138.

34. Jennette JC. Rapidly progressive crescentic glomerulonephritis. Kidney Int. 2003;63:1164-77.

35. Grossfeld GD, WolfJS Jr, Litwan MS, Hricak H, Shuler CL, Agerter DC, Carroll PR. Asymptomatic microscopic hematuria in adults: Summary of the AUA best practice policy recommendations. Am Fam Physician. 2001;63:1145-54.

36. Levey AS, de Jong PE, Coresh J, El Nahas M, Astor BC, Matsushita K, Gansevoort RT, Kasiske BL, Eckardt KU. The definition, classification, and prognosis of chronic kidney disease: A KDIGO Controversies Conference report. Kidney Int. 2011;80:17-28.

37. Cortazar FB, Kibbelaar ZA, Glezerman IG, Abudayyeh A, Mamlouk O, Motwani SS, Murakami N, Herrmann SM, Manohar S, Shirali AC, Kitchlu A, Shirazian S, Assal A, Vijayan A, Renaghan AD, Ortiz-Melo DI, Rangarajan S, Malik AB, Hogan JJ, Dinh AR, Shin DS, Marrone KA, Mithani Z, Johnson DB, Hosseini A, Uprety D, Sharma S, Gupta S, Reynolds KL, Sise ME, Leaf DE. Clinical Features and Outcomes of Immune Checkpoint Inhibitor-Associated AKI: A Multicenter Study. J Am Soc Nephrol. 2020;31:435-46.

38. Zammouri A, Barbouch S, Najjar M, Aoudia R, Jaziri F, Kaaroud H, Hedri H, Abderrahim E, Goucha R, Hamida FB, Harzallah A, Abdallah TB. Tubulointerstitial nephritis due to sarcoidosis: Clinical, laboratory, and histological features and outcome in a cohort of 24 patients. Saudi J Kidney Dis Transpl. 2019;30:127684 .
39. Zajjari Y, Azizi M, Bahadi A, Montasser D, Aatif T, Alayoud A, El Kabbaj D. Granulomatous interstitial nephritis in the military hospital of Morocco: Causes and outcomes. Saudi J Kidney Dis Transpl. 2020;31:589-96.

40. Bajema IM, Hagen EC, van der Woude FJ, Bruijn JA. Wegener's granulomatosis: A meta-analysis of 349 literary case reports. J Lab Clin Med. 1997;129:17-22.

41. Unlu M, Kiremitci S, Ensari A, Ozluk Y, Kilicaslan I, Ozdemir BH, Ates D, Ertoy Baydar D, Gonul, II, Memis L, Sarsik B, Sen S, Akkaya B, Orhan D, Gonlusen G, Ellidokuz H, Ada S, Cavdar C, Akagun T, Kamali S, Aksu K, Yazisiz V, Paydas S, Soylu A, Sarioglu S. Pauci-immune necrotizing crescentic glomerulonephritis with crescentic and full moon extracapillary proliferation: Clinicopathologic correlation and follow-up study. Pathol Res Pract. 2013;209:75-82.

42. Eastwood JB, Corbishley CM, Grange JM. Tuberculosis and the kidney. J Am Soc Nephrol. 2001;12:1307-14.

43. Agrawal V, Kaul A, Prasad N, Sharma K, Agarwal V. Etiological diagnosis of granulomatous tubulointerstitial nephritis in the tropics. Clin Kidney J. 2015;8:524-30.

44. Larsen CP, Moreira RK, Hennigar RA, Bijol V. Kidney biopsy findings in a patient with fever, bilateral pulmonary infiltrates, and acute renal failure. Am J Kidney Dis. 2008;51:524-9.

45. Davidson B, Nel D, Jones ESW, Manning K, Spies R, Bohmer R, Omar A, Ash S, Wearne N. Granulomatous interstitial nephritis on renal biopsy in human immunodeficiency virus positive patients: Prevalence and causes in Cape Town, South Africa. Nephrology. (Carlton) 2019;24:681-8.

46. Karmakar S, Basu K, Sengupta M, Sircar D, Roychowdhury A. Granulomatous Interstitial Nephritis - A Series of Six Cases. Indian J Nephrol. 2020;30:26-8.

47. Farris AB, Ellis CL, Rogers TE, Chon WJ, Chang A, Meehan SM. Renal allograft granulomatous interstitial nephritis: Observations of an uncommon injury pattern in 22 transplant recipients. Clin Kidney J. 2017;10:240-8.

48. Vargas F, Gedalia A, Craver RD, Matti Vehaskari V. Recurrence of granulomatous interstitial nephritis in transplanted kidney. Pediatr Transplant. 2010;14:e54-7.

49. Teranishi J, Hattori Y, Mochizuki T, Kawahara T, Makiyama K, Uemura H. Effective Treatment With Everolimus for Recurrent Granulomatous Interstitial Nephritis in a Renal Transplant Recipient: A Case Report. Transplant Proc. 2016;48:946-8.

50. Murtaza A, Ali H, Nair B, Ahmed AK. Recurrence of Tubulointerstitial Nephritis Without Uveitis, in a Patient with Previous Tubulointerstitial Nephritis and Uveitis Syndrome After Transplant. Exp Clin Transplant. 2018;16:216-8.

51. Onyekpe I, Shenoy M, Denley H, Riad H, Webb NJ. Recurrent tubulointerstitial nephritis and uveitis syndrome in a renal transplant recipient. Nephrol Dial Transplant. 2011;26:3060-2.

52. Khaira A, Bagchi S, Sharma A, Mukund A, Mahajan S, Bhowmik D, Dinda AK, Agarwal SK. Renal allograft tuberculosis: Report of three cases and review of literature. Clin Exp Nephrol. 2009; 13:392-6. 
53. Javaud N, Belenfant X, Stirnemann J, Laederich J, Ziol M, Callard P, Ronco P, Rondeau E, Fain O. Renal granulomatoses: A retrospective study of 40 cases and review of the literature. Medicine. (Baltimore) 2007;86:170-80.

54. Mignon F, Mery JP, Mougenot B, Ronco P, Roland J, MorelMaroger L. Granulomatous interstitial nephritis. Adv Nephrol Necker Hosp. 1984;13:219-45.

55. Naidu GD, Ram R, Swarnalatha G, Uppin M, Prayaga AK, Dakshinamurty KV. Granulomatous interstitial nephritis: Our experience of 14 patients. Indian J Nephrol. 2013;23:415-8.

56. Viero RM, Cavallo T: Granulomatous interstitial nephritis. Hum Pathol. 1995;26:1347-53.

57. Alsaad KO, Tobar A, Belanger E, Ahmad M, Cattran DC, Herzenberg AM. Late-onset acute haemorrhagic necrotizing granulomatous adenovirus tubulointerstitial nephritis in a renal allograft. Nephrol Dial Transplant. 2007;22:1257-60.

58. al-Sulaiman MH, Dhar JM, al-Hasani MK, Haleem A, al-Khader A. Tuberculous interstitial nephritis after kidney transplantation. Transplantation. 1990;50:162-4.

59. Asim M, Chong-Lopez A, Nickeleit V. Adenovirus infection of a renal allograft. Am J Kidney Dis. 2003;41:696-701.

60. Aouizerate J, Matignon M, Kamar N, Thervet E, Randoux C, Moulin B, Raffray L, Buchler M, Villar E, Mahevas M, Desvaux D, Dahan K, Diet C, Audard V, Lang P, Grimbert P. Renal transplantation in patients with sarcoidosis: A French multicenter study. Clin J Am Soc Nephrol. 2010;5:2101-8.

61. Baden LR, Digumarthy SR, Guimaraes AS, Branda JA. Case records of the Massachusetts General Hospital. Case 352009. A 60-year-old male renal-transplant recipient with renal insufficiency, diabetic ketoacidosis, and mental-status changes. N Engl J Med. 2009;361:1980-9.

62. Bagnasco SM, Subramanian AK, Desai NM. Fungal infection presenting as giant cell tubulointerstitial nephritis in kidney allograft. Transpl Infect Dis. 2012;14:288-91.

63. Barraclough K, Oliver K, Playford EG, Preston J, Campbell S, Johnson DW, Hawley C, Mudge D, van Eps C, Isbel N. Lifethreatening adenovirus infection in a kidney transplant recipient. NDT Plus. 2009;2:250-3.

64. Brown JH, Jos V, Newstead CG, Lawler W. Sarcoid-like granulomata in a renal transplant. Nephrol Dial Transplant. 1992;7:173.

65. Gaspert A, Luthi B, Mueller NJ, Bossart W, Heim A, Wuthrich RP, Fehr T. Subacute allograft failure with dysuria and hematuria in a kidney transplant recipient. Am J Kidney Dis. 2009;54:154-8.

66. Gonçalves AR, Caetano MA, Paula FJ, Ianhez LE, Saldanha LB, Sabbaga E. Tuberculous interstitial granulomatous nephritis in renal transplants: Report of three cases. Transplant Proc. 1992;24:1911.

67. Hatlen T, Mroch H, Tuttle K, Ojogho O, Rooney M, Desmond S, Bani-Hani S. Disseminated Adenovirus Nephritis After Kidney Transplantation. Kidney Int Rep. 2018;3:19-23.

68. Hotta K, Fukasawa Y, Sasaki H, Seki T, Togashi M, Harada H. Granulomatous tubulointerstitial nephritis in a renal allograft: Three cases report and review of literature. Clin Transplant. 2012;26 Suppl 24:70-5.
69. Josephson MA, Chiu MY, Woodle ES, Thistlethwaite JR, Haas M. Drug-induced acute interstitial nephritis in renal allografts: Histopathologic features and clinical course in six patients. Am J Kidney Dis. 1999;34:540-8.

70. Kukura S, Viklicky O, Lacha J, Voska L, Honsova E, Teplan V. Recurrence of sarcoidosis in renal allograft during pregnancy. Nephrol Dial Transplant. 2004;19:1640-2.

71. Lachiewicz AM, Cianciolo R, Miller MB, Derebail VK. Adenovirus causing fever, upper respiratory infection, and allograft nephritis complicated by persistent asymptomatic viremia. Transpl Infect Dis. 2014;16:648-52.

72. Lapasia JB, Kambham N, Busque S, Tan JC. Renal allograft granulomas in the early post-transplant period. NDT Plus. 2010;3:397-401.

73. Lorimer I, Botha J, Pontin AR, Pascoe MD, Kahn D. Tuberculosis isolated to the renal allograft. Transpl Infect Dis. 1999;1:83-6.

74. Meehan SM, Josephson MA, Haas M. Granulomatous tubulointerstitial nephritis in the renal allograft. Am J Kidney Dis. 2000;36:E27.

75. Ozdemir BH, Sar A, Uyar P, Suren D, Demirhan B, Haberal M. Posttransplant tubulointerstitial nephritis: Clinicopathological correlation. Transplant Proc. 2006;38:466-9.

76. Parasuraman R, Zhang PL, Samarapungavan D, Rocher L, Koffron A. Severe necrotizing adenovirus tubulointerstitial nephritis in a kidney transplant recipient. Case Rep Transplant. 2013;2013:969186.

77. Park UJ, Hyun SK, Kim HT, Cho WH, Han SY. Successful treatment of disseminated adenovirus infection with ribavirin and intravenous immunoglobulin in an adult renal transplant recipient: A case report. Transplant Proc. 2015;47:791-3.

78. Shen SY, Hall-Craggs M, Posner JN, Shabazz B. Recurrent sarcoid granulomatous nephritis and reactive tuberculin skin test in a renal transplant recipient. Am J Med. 1986;80:699-702.

79. Storsley L, Gibson IW. Adenovirus interstitial nephritis and rejection in an allograft. J Am Soc Nephrol. 2011;22:1423-7.

80. Sujeet K, Vasudev B, Desai P, Bellizzi J, Novoa-Takara L, He C, El-Meanawy A. Acute kidney injury requiring dialysis secondary to adenovirus nephritis in renal transplant recipient. Transpl Infect Dis. 2011;13:174-7.

81. Tse KC, Chan TM, Wong SS, Chan KW, Lam MF, Chan KH, Li FK, Choy BY, Lai KN. Granulomatous interstitial nephritis of the allograft kidney associated with rhodococcal pulmonary infection. Nephrol Dial Transplant. 2004;19:486-90.

82. Varma MC, Kushner YB, Ko DS, Kawai T, Martins PN, Kaur P, Markmann JF, Kotton CN. Early onset adenovirus infection after simultaneous kidney-pancreas transplant. Am J Transplant. 2011;11:623-7.

83. Veer M, Abdulmassih R, Como J, Min Z, Bhanot N. Adenoviral nephritis in a renal transplant recipient: Case report and literature review. Transpl Infect Dis. 2017;19.

84. Zhang Y, Ahmed H, Haririan A, Ugarte R, Papadimitriou JC, Drachenberg CB. Granulomatous inflammation in BK polyomavirus-associated nephropathy. Transpl Infect Dis. 2018;20:e12939. 